\title{
Gender Discrimination and Women Career in Imo State: A Case Study of Imo State University, Owerri
}

\author{
Emmanuel A. Eboh \\ Department of Sociology, Imo State University, Owerri, Nigeria \\ Email: emmanueleboh2015@gmail.com
}

How to cite this paper: Eboh, E. A. (2021). Gender Discrimination and Women Career in Imo State: A Case Study of Imo State University, Owerri. Advances in Applied Sociology, 11, 453-469.

https://doi.org/10.4236/aasoci.2021.119040

Received: September 28, 2020

Accepted: September 25, 2021

Published: September 28, 2021

Copyright ( 2021 by author(s) and Scientific Research Publishing Inc. This work is licensed under the Creative Commons Attribution International License (CC BY 4.0).

http://creativecommons.org/licenses/by/4.0/

\section{(c) (i) Open Access}

\begin{abstract}
In this paper, we carry out two types of analyses namely descriptive and inferential analyses to determine the effect of gender on career choices, employment and promotion of the staff in Imo State University, Owerri. The descriptive statistical analysis indicates fair gender balance in the university with respect to staff's career choice, employment and promotion. This was based on the sample data. From the inferential analysis obtained from the three hypotheses stated and tested in this study, there were strong indications that gender consideration is significant in career choices, employment but not promotion in Imo State University, Owerri. Hence, this research does not support the claim that there is gender discrimination against women.
\end{abstract}

\section{Keywords}

Gender Discrimination, Gender Gap, Career Choices, Inferential Analysis, Descriptive Analysis

\section{Introduction}

Obviously, there is a gender gap in some selected disciplines and leadership positions in so many areas of life. This gap or discrimination is believed to be against women. Sociologists are trying to unravel the source of gender gap and remedies to close the gap. In the literatures on career gender gap, so many factors were implicated. Some researchers and sociologists believed that culture placed preference for men against women. In so many cultures, especially in the developing and underdeveloped countries, men are giving more opportunities than the women. This single fact made women to shy away from leadership positions and scared of competition. For example in Nigeria, women shy away from contesting 
for political positions due to the fear of men's dominance. Women cannot also endure the rough nature of Nigerian politicking and hence resort to political appointment and campaign for a giving percentage of political posts. It was argued that women do not often engage in some courses that have mathematics, (Correll, 2001), as its base, such courses include engineering, physical sciences, computer sciences, space sciences, etc., rather, they mostly engage in those courses that do not require mathematics. These are mostly the bases for career and earning inequality. Some argued that culture and nature of women influence them to take more of lower and humanitarian courses that do not attract high pay. It should be noted that the forces of demand and supply determine the price irrespective of sex. The harder the course, the fewer the number of people who apply to and offer it at the university level and hence the more it attracts a higher pay.

It is indeed worrisome that irrespective of the increasing number of women in labour force, sex segregation in the workforce continues, (Callahan, 2015), despite the removal of the structural barriers that once kept women from entering some careers. It was argued that men have biological aptitude for mathematics than women and that made men to choose those majors that have prestige and pay more. I did not buy this line of thought, the reason is that it has not been proven that men are more gifted in terms of brain capacity and understanding than women, it all depend on focus, resilience and determination. Mathematics requires patience, focus more time and constant study for a beginner but many women do not have these quality. Since mathematics is the mother of all sciences and technology, those with the background have access to science based courses which pay better irrespective of gender. Gender disparity is all about attitude which determines career choices. In the university system, equal job attracts equal pay irrespective of gender.

In many cases, women as mothers do not take on some careers because they are home builders. There natural role drive them away from some careers that people see as jobs for men. For instance, it will be hard to see a woman in the discipline such as aircraft engineer, marine engineer, space scientists, etc. This is not that women cannot read those courses but the requirements and practices of such jobs are enormous for a mother who will always rear children. Hence, courses of such nature are called men's courses and a career in such area that is short in supply will not only be prestigious but attracts higher earnings. Respondents in a study done by (Raggl \& Troman, 2008) pointed out that becoming mother changed their orientation in life completely. Despite their previous careers in non-traditional female occupations and their strong commitment to work before turning to motherhood, they decided to remain at home and exchanged their high-status careers for a caring role.

Women have complained so much about discrimination against them in socio-economic and political life. In social life, women are prohibited from holding some positions. Researchers blame this imbalance on religion, which subject women 
to men. In this case, gender discrimination against women is as old as man itself. They argue that culture promotes discrimination against women. In many cultures, women are not allowed to hold certain positions, they are seen as secondhand. In some cultures, women do not inherit land there by denying them an important economic right. All over the world, with the exception of few countries, women are not allowed to lead them as President, Prime Minister, Head of State, etc. This is a bad omen for women. But in majority of cases, women discriminate against themselves. One would expect that with the numerical strength of women, that a women president could emerge but the reverse is always the case because women vote against themselves in preference for men. In reality, women would rather want men to lead instead of their fellow women. Women shy away from leadership position, maybe it is in their nature.

The interest of this paper is on Imo State Nigeria and since Imo State University is made up of staff across the 27 local government areas in the state, we see it as a representation of workers in Imo State. Therefore, we select Imo State University (IMSU) as a case study.

Imo State University has staff strength of one thousand four hundred and seventy-seven staff (1477) composed of six hundred and twenty-three (623) academic staff and eight hundred and fifty-four (854) non-academic staff. The university has ten (10) faculties, namely: 1) Agric and Veterinary medicine; 2) Business Administration; 3) Education; 4) Engineering; 5) Environmental Sciences; 6) Health Sciences; 7) Humanities; 8) Social Sciences; 9) Biological Sciences and 10) Physical Sciences. The university has over ten (10) directorates and the researcher considered all the staff interest while carrying out this work.

In this study, we examine the motive behind career choices between men and women to determine if they depend on the gender. As the argument against career gender discrimination rages, this study aimed at determining whether some careers are exclusively left for any particular gender. In the same vein, the study will seek to determine whether employment into various areas of civil or public service in Nigeria is gender based or not. And finally, the researcher wants to determine whether promotion from work place is gender dependent or not. Answer to these research questions will help to address some basic issues relating to gender discrimination as it is believed.

In this paper, our aim is to carry out both descriptive and inferential statistics to determine if there is gender discrimination against women in general. In trying to achieve this aim, the researcher carries out percentage analysis, state research hypotheses and tests the hypotheses using Chi-square as a test statistic. The researcher will make conclusion based on the result of the analysis. This paper is divided into five sections. Section one above gives the general introduction and background of the work. Section two is devoted to literature review. Section three takes care of materials and methods. Section four takes care of data presentation and analysis while section five treats results and discussions. 


\section{Research Questions}

This study aims at providing answers to the following specific research questions:

1) Are career choices of the staff of Imo State University independent of gender?

2) Is employment of staff independent of gender in Imo State University?

3) Is staff promotion in Imo State University independent of gender?

\section{Literature Review}

(Correll, 2001) observed that cultural beliefs about gender and task competence at various skills influence career choices. The author examine how gender differences in the perception of mathematical competence influence high school and college students' educational decisions that lead to careers in engineering, math, and the physical sciences. The career choice process occurs throughout the life cycle as individuals make a series of decisions that have occupational consequences. Those who fail to take advanced-level math classes in high school are highly unlikely to select college majors in science, math, or engineering. It was observed that the ratio of females to males declines as young people move further down the path toward the quantitative professions. By high school, males are more likely than females to be enrolled in advanced-level math and science elective classes. It was believed that shortage of women in the quantitative professions is that males have a biological aptitude for math that females lack. But Sociologists have realized that gender is a multilevel system that consists not only of roles and identities at the individual level, but also includes ways of behaving in relation to one another at the interactional level, and cultural beliefs and distributions of resources at the macro level. The multilevel nature of this system allows processes that contribute to the reproduction of gender inequality at the macro, micro, and interactional levels to occur simultaneously. In this way, the gender system is enthroned and represents a powerfully conservative system. Many studies have shown that students view math as masculine and perceive mathematics to be a male domain. The outcome is that males will overestimate and females will underestimate their own mathematical ability. Females are less likely than males to perceive that they are good at a task, this reduce their efforts and interests in activities requiring competence at the task.

(Callahan, 2015) was of the opinion that career choices are among the most important choices made by an individual in his or her lifetime. One's career often represents a significant part of identity and is information often sought by others. He observed that despite reduction or removal of the structural barriers that once kept women from entering some careers, sex segregation in the workforce continues. Women and men tend to seek and enter different careers; however, reasons for this continued discrepancy are still unclear. The number of women in the workforce has increased dramatically over time. Women have also approached equality with men in a number of areas. But in spite of this clear evidence of progress made by women, women are still underrepresented in tra- 
ditionally masculine careers such as math- and science-related fields and overrepresented in traditionally feminine careers such as clerical and service fields. Furthermore, careers chosen by women in large numbers are often those careers that have lower prestige, status and salary than their male counterparts. If structural barriers to the equal employment of women are currently absent or weakened, it would seem possible for women to reach this equal employment and to reduce sex segregation in the workforce. In the course of research, it was discovered that women tend to be overrepresented in traditionally feminine occupations that also tend to be lower in pay and prestige, while men tend to be overrepresented in traditionally masculine careers with greater pay and prestige. The author examined perceptions of the femininity and masculinity of the job types, with the assumption that gendered views of occupations may impact individual decision-making related to careers. Given the importance of gender as a social and psychological construct, individuals consistently view the job types as either feminine or masculine. The researcher observed that people consistently perceived the Social type of job as more feminine and the Realistic type of job as more masculine. The researcher; however, was of the opinion that shifts in the perceptions of the femininity and masculinity of some job types are possible when individuals are exposed to women or men in representative jobs.

On the other hand, (Raggl \& Troman, 2008) observed that equal opportunities and practices aimed at increasing female participation in the workforce. Some researchers were of the view that these conditions offer new choices in careers and life. The researcher pointed out that out of 18 career changers within the Economic and Social Research Council project, Primary Teacher Identity, Commitment and Career in Performative School Cultures who entered teaching from different private-sector occupations, 15 were women and three were men. These figures represent the predominantly female composition of the primary teaching workforce. It is argued that this workforce is becoming increasingly feminized in terms of numbers. The researchers were interested in the bases on which these choices are made and the impact of gender and other influencing factors on career decisions. The present analysis of female and male career changers narratives revealed that their career plans were provisional and changeable, and that individuals constructed their own career paths according to the realities they found themselves at particular times of their life. Their career decisions were influenced by personal and family stage, structural factors and unexpected life events such as redundancy. Respondents from this research pointed out that becoming mother changed their orientation in life completely. They said that despite their previous careers in non-traditional female occupations and their strong commitment to work before turning to motherhood, they decided to remain at home and exchanged their high-status careers for a caring role at home in a society which devalues caring jobs.

(Buser et al., 2014) document large gender differences in competitiveness based on laboratory experiments that women shy away from competition, while men 
often compete too much. It was proposed that these gender differences in competitiveness may help explain gender differences in actual education and labor market outcomes. They were of opinion that Math and science intensity is one of the most significant dimensions of gender differences in educational choices. In many countries, girls are less likely than boys to choose mathematics and science heavy courses in secondary education. They observed that in the United States, a gender difference in math and sciences manifests itself at the college level, where women are significantly less likely than men to graduate with a major in science, technology, engineering, or mathematics. Performance in mathematics also predicts future earnings. In an experiment carried out by the authors, the students exhibit the expected gender differences. Although the academic performance of girls (including math grades) is at least as good as that of boys, boys choose substantially more prestigious academic tracks than girls. Also, while the performance of boys and girls on the experimental task is very similar, boys are twice as likely as girls to choose the competitive payment scheme. They showed that the effect of competitiveness is not driven by a possible effect of confidence or risk attitudes on academic track choice.

(Herrbach \& Mignonac, 2012) saw career as the unfolding sequence of a person's work experiences over time. Women are faced with specific challenges that may prevent their career goals, such as related family duties. They observed that women are likely to be limited by family factors including childbearing, prioritization of the husband's career and by the related continuous organizational employment such as career gaps and relocations. These may prevent women from reaching their career goals. Again, women exhibit lower managerial ambitions compared to men because they anticipate their family duties or they align themselves with social roles expected from women. The authors were concerned with the discrimination in the workplace, whereby women are prevented from success, not because of their real choices but because of the treatment they receive from organizations. Gender gap in career success was attributed to sex discrimination and not to differences in human capital, individual characteristics, or contextual factors. Women reported gender discrimination as the most frequent barrier to their advancement at all managerial levels. The authors were of the opinion that perceived discrimination could be an important factor that influences how women figure out whether or not they have satisfactorily satisfied their career needs. Perceived discrimination creates doubt in the minds of employees as to whether they are likely to achieve their economic goals and this also negatively relates to a person's sense of social standing. In the case of gender discrimination, this may explain why women's subjective career success should be related to the amount of discrimination they have faced, because being discriminated against leads to a sense of not having achieved the symbolic and economic sense of success that could have been achieved otherwise. From their work, the authors found that subjective career success is negatively associated with perceived gender discrimination. They were of the opinion that some life- 
style enhances the impact of perceived gender discrimination but security and autonomy lessen it. Women who score higher in the lifestyle react more strongly to perceived gender discrimination.

(Tang et al., 2008) observed that years spent in school; the number of science and math courses taken in high school was positively related to the choice of science and math as majors when entering college. Again, understanding college requirements and self-efficacy in math and science are found to be more positively related to remaining in the chosen field. The researchers were of the opinion that at adolescents, students developed two cognitive competencies related to career development namely; self-concept and perceptions about occupations. At this period, students also have achieved an adult-level understanding of the sex type and prestige level of common occupations. Adolescents start to eliminate occupational choices based on sex types and prestige levels. It was observed that women avoid male-dominated occupations due to a lack of self-confidence in such occupations, and that this lack of confidence is rooted in a lack of encouragement, role models, or similar experiences in the field. The results from their analysis show that high school girls, compared with their male counterparts, were more interested in occupations that involve working with people and ideas. The high school girls were also found more likely to choose occupations that involve helping others and expressing oneself. In contrast, boys were more interested in higher self-efficacy and more likely to choose occupations involving data and things. Male students avoid people/ideas types of occupations even though they have interests in those areas. Like females, male students need strong self-efficacy to pursue nontraditional occupations.

Also, (Gibson \& Lawrence, 2010) observed that many research show consistent evidence that women have lower career expectations than men about formal organizational rewards. These lower expectations lead to lower actual rewards thereby providing answer on why women's careers lag behind those of their male counterparts. The primary explanation for women's lower expectations involves their career referents. Both women and men tend to make upward comparisons to career referents at higher levels than their own because such referents provide inspiration about possible achievement and information about how to perform better. However, women's career referents diverge from men's in two ways. First, women tend to see their careers as similar to those of other women, whereas men see their careers as similar to those of other men. Using same-gender comparisons to determine career expectations makes sense because individuals assume that such referents are similar in attributes related to achievement, such as background qualifications, work experiences, education, or family concerns, and are thus appropriate for accurate appraisals of likely achievement. Second, women's career referents tend to be at lower levels than men's in their career accomplishments. They opined that women frequently earn less money than men and consistently receive fewer promotions than men; this occur independent of occupation. Thus, when a woman selects women as career referents, 
they tend to make less money and hold lower-level jobs than the men selected by a man. Using this reasoning, women's career expectations tend to remain lower than men's because expectations depend on the comparison level of one's career referents. Thus the authors test the hypothesis that women set the bar of identifying referents low and that raising this bar will increase expectations. They found that higher levels of career referents are related to higher career expectations. And that women do not increase their expectations to the same degree as men do in response to observing high-achieving others. Generalizing the result of this research, it raises questions about whether the standard managerial solution of providing women with more role models in high-status jobs will work.

(Fluhr et al., 2017) noted that the labour force in the United States has undergone a drastic change due to steadily increasing female workforce participation. As a result, the gender gap in the workforce has narrowed down but male participation rates still exceed those of women. This relative balance, however, has done little to change the gender composition of specific careers, which remain heavily segregated along gender lines. The researchers observed that occupations are still readily identifiable, as either male-dominated or female-dominated. This occupational gender segregation has serious social and economic implications. They opined that in the higher-paying Science, Technology, Engineering and Mathematics (STEM) fields, the majority of its employees and students are male. Female-dominated occupations typically offer lower economic opportunities in terms of salary and earnings potential and carry a presumption of lower social status. Conversely, male-dominated fields have historically offered higher salary and benefits as well as higher social status within society at large. The concentration of women in lower paying fields in general has led to the proliferation of a gender wage gap that continues to favor men. They observed that the gender wage gap is not merely a social or economic justice issue. Research indicates that several socio-cultural factors contribute to the gender divide in the work force. When examining gender wage gaps resulting from program area choice, the results of this study suggest that gender wage gap differs by program area, with some program areas, exhibiting greater wage gaps by gender in comparison to other program areas. Males were actually more likely to pursue enrollment in nontraditional courses of study than females. This implies that program area is an important factor in wage differentials. This suggests that the continuation of targeted recruitment to specific programs of study might prepare students for highwage careers that will further narrow the existing gender wage gap. The authors suggested that students should be provided with clear information about the wage earnings they can expect in various occupations, so that they can make informed choices early on when they are deciding among courses.

(Conner et al., 2014) inquired on what keeps women out of leadership jobs in academic medicine. They observed that women on medical faculties may prefer teaching and treating patients to publishing research papers. Women's service motivations explain their down shift to the clinician-educator track. Studies also 
reveal how attributing work place inequities to women's preferences distracts observers from unfair institutional practices. It was reported that professional women who viewed their move to stay-at-home mother hood as a personal choice, as compared to new full-time moms who did not view their move as a choice, less often cited discrimination, harassment, and family-unfriendly policies as sources of gender inequality. Other studies similarly demonstrate that framing unequal outcomes as the result of individual choices, rather than of institutional or societal forces, deadens empathy and delays action. The authors were of the opinion that in order to help end gender inequities, all publications must take greater care when reporting about women in science. But in opposition to this assertion, another researcher said that he strongly deplore and oppose bias and discrimination of any kind in science. He was of the view that his colleagues and he work assiduously to help female (and male) scientists and aspiring scientists advance in the careers of their choosing. In line with that goal, he report on research that helps scientists of both genders understand the career opportunities that currently exist so that they can make choices that maximize their chances of finding and prospering in positions that fit their values, goals, aspirations, and definitions of success.

Women in the United States, (Mullen, 2014), have been graduating from college at higher rates than men but major fields of study remain sharply divided by gender. The trend narrow down the gender gap dramatically but there has been little movement toward the gender integration of majors. However, it was noticed that not all students that attend university have the primary objective of career preparation. While students from lower socioeconomic origins do tend to perceive a college education chiefly as a route to improved employment opportunities, students from more affluent backgrounds are more likely to regard their undergraduate education not simply as a training ground for jobs but as a time for learning and personal growth. The manner in which students connect their college major to their future occupational plans vary, from explicit and direct connections, to less direct links, lack of consideration of possible careers to which a major might altogether lead to, and how students approach the choice of major relates to gender and social background. A good number of students enter vocational or pre-professional majors, but majority of them choose liberal arts fields, most of which have only indirect links, if any, to specific occupations. Further, qualitative and survey research finds that students' motivations for attending college vary. Some students do perceive a college education primarily as career preparation, but many students go to college not to receive training for a specific job but for broader learning. Thus, the current conceptualization of major choice may be appropriate for those students attending college primarily to prepare for a specific career but may be less suitable for their privileged peers attending university for broader set of reasons. The researcher observed that privileged men view their education as a means to re-create their families' affluent class status and begin to gravitate toward lucrative fields in anticipation of taking on the re- 
sponsibility for supporting their future families. In aligning their choices with these masculine, men manage a more complex set of considerations and a more constrained range of options than do most women, they create a balance between what they would like to study and what they feel they need to study.

There are significant difference in the choices of career between males and females, (Zafar, 2013). These markedly different choices in college major between males and females have significant economic and social impacts. Empirical studies have shown that large earnings premiums exist across majors. In the United States, the average education major employed full-time earned only 60 percent as much as one who majored in engineering. Gender differences in choice of major have recently been at the center of hot debate on the reasons behind women's underrepresentation in science and engineering. It was suggested in the first case that innately disparate abilities between males and females may predispose each group to choose different fields. Males and females have similar preferences regarding outcomes but differ in their tastes regarding the workplace.

\section{Hypothesis (1)}

Ho: Career choices of staff of Imo State University are independent of gender.

H1: Career choices of staff of Imo State University are dependent of gender.

\section{Hypothesis (2)}

Ho: Employment of the staff of Imo State University is independent of gender.

H1: Employment of the staff of Imo State University is dependent of gender.

\section{Hypothesis (3)}

Ho: Staff promotion in Imo State University is independent of gender.

H1: Staff promotion in Imo State University is dependent of gender.

\section{Materials and Methods}

This section focuses on the research design, population of study, sample and sampling techniques, research instrument, validity and reliability of instrument, administration of the instrument and method of data analysis.

\subsection{Research Design}

The research design adopted in this study is the survey research design. Since the problem of gender imbalance is a social problem that need direct responses from the target population (the staff of Imo State University, Owerri Imo State), the researcher need to go to the field to ascertain the direct impulse of the target population on the matter under study. Hence, the researcher went to the field and interacted with the respondents and obtained data from them for this study.

\subsection{Population of Study/Type of Data}

The population of study includes the entire staff of Imo State University, Owerri Imo State. The data collected from the respondents is a primary data. It is primary data because the researcher collected these data by himself. 


\subsection{Sampling Technique Used}

The researcher made use of simple random sampling technique in selecting his sample for the study. Simple random sampling technique is a probability sampling that gives every unit of the population equal chances of being selected, Arua et al. (1997). It is one of the most widely used methods of sampling. Hence, the sample for the study was thrown open to all staff and data was obtained from them through the use of questionnaires.

\section{Sample Size Determination}

To get the sample size for this study, the researcher the statistical formula, (Taro, 1967), given below:

$$
n=\frac{N}{1+N(e)^{2}}
$$

where:

$$
\begin{aligned}
& n=\text { sample size } \\
& N=\text { Population size; } \\
& e=\text { allowable error }(0.05) ; \\
& 1=\text { constant }
\end{aligned}
$$

$$
n=\frac{1477}{1+1477(0.05)^{2}}=315
$$

Therefore, the sample size used for this study is 315 staff of the Imo State University. This sample size formed the basis of inference about the entire population of study.

\subsection{Research Instrument}

The instrument used for the data collection is the questionnaires. The researcher designed questionnaire based on the area he wants to investigate and administered it to the staff using the simple random technique. Two departments were randomly drawn from each faculty, hence; out of ten (10) faculties, twenty (20) departments were drawn. The researcher also draws five (5) directorates for the distribution of the questionnaires. Since we have determined the sample size for the study to be three hundred and fifteen (315), three hundred and fifteen (315) questionnaires were distributed to the respondents in the selected departments and directorates to fill and return. Out of these numbers, three hundred and eleven (311) were correctly filled and returned. Hence, the sample size for this study is three hundred and eleven (311).

\subsection{Validity of the Research Instrument}

The questionnaires were cross checked by statistician who certifies it okay before it was administered to the respondents. Some questions that do not conform to the researcher's area of interest were removed and others added where necessary. Hence, the research instrument was validated before the researcher began to use it. 


\subsection{Method of Data Analysis}

In the course of this research, the researcher applied both descriptive and inferential statistics to analyze the data. In descriptive analysis, he applied frequency tables and percentages to analyze the data. In inferential statistics, he applied Chi-square and contingency table to test some hypothesis stated in this study. The researcher tested the hypothesis on the dependent or independent of the gender on career choices, employment and promotion of staff.

The Chi-square is given in Equation (1) as:

$$
\chi_{\text {cal }}^{2}=\sum_{i=1}^{n} \sum_{j=1}^{m} \frac{\left(O_{i j}-E_{i j}\right)^{2}}{E_{i j}} \sim \chi_{(c-1)(r-1)}^{2} \alpha
$$

where $O_{i j}=$ observed values; $E_{i j}=$ expected values; $c$ and $r$ are number of columns and rows respectively; $\alpha=$ the level of significance; $c a l=$ calculated; $\chi^{2}$ the Chi-square test statistic.

$E_{i j}$ is computed as follows:

$$
E_{i j}=\frac{R_{i} \times C_{j}}{n}
$$

where $E_{i j}$ is the expected value; $R_{i}$ is the row total and $C_{j}$ is the column total and $n$ is the grand total.

\section{Data Presentation, Analysis and Result}

\subsection{Data Presentation}

The data collected from the respondents were presented in Tables 1-8. Each of the Tables is labeled A to E. Each alphabet represent a scale of response, here we have five scales, where " $A$ " represent strongly agree, " $B$ " represent agree, " $\mathrm{C}$ " represent strongly disagree, " $D$ " represent disagree and " $E$ " represent undecided. These Tables are called contingency Tables with the observations in each cell.

\subsection{Data Analysis}

\section{Descriptive Analysis}

From Table 4, we observed that $43.73 \%$ were of the opinion that they were not influenced by gender while making their career choices, while $40.84 \%$ of the

Table 1. Responses of staff on career choices.

\begin{tabular}{ccccccc}
\hline Schools & A & B & C & D & E & Total \\
\hline 1 & 18 & 20 & 17 & 20 & 10 & 85 \\
2 & 14 & 19 & 15 & 15 & 15 & 78 \\
3 & 20 & 14 & 15 & 13 & 13 & 75 \\
4 & 14 & 17 & 16 & 16 & 10 & 73 \\
Total & 66 & 70 & 63 & 64 & $\mathbf{4 8}$ & 311 \\
\hline
\end{tabular}

Source: survey result from Imo State University, 2020. 
staff believed that they were influenced by their gender in the choice of their respective careers. On the other hand, $15.43 \%$ were undecided on whether gender influenced their career choices or not.

From Table 5, we observed that $47.59 \%$ were of the opinion that their employment was independent of their gender, while $37.30 \%$ of the staff believed that their employment was based on their gender. Moreover, $15.11 \%$ were undecided on whether their gender influenced their employment or not.

From Table 6, we observed that $47.27 \%$ were of the opinion that their promotion was independent of their gender, while $40.19 \%$ of the staff believed that their promotion was based on their gender. Again, $12.54 \%$ were undecided on whether their gender influenced their promotion or not.

Table 2. Responses of staff on employment condition.

\begin{tabular}{ccccccc}
\hline Schools & A & B & C & D & E & Total \\
\hline 1 & 15 & 19 & 15 & 14 & 14 & 77 \\
2 & 16 & 13 & 18 & 11 & 10 & 68 \\
3 & 19 & 26 & 13 & 17 & 11 & 86 \\
4 & 18 & 22 & 15 & 13 & 12 & 80 \\
Total & $\mathbf{6 8}$ & $\mathbf{8 0}$ & $\mathbf{6 1}$ & $\mathbf{5 5}$ & $\mathbf{4 7}$ & 311 \\
\hline
\end{tabular}

Source: survey result from Imo State University, 2020.

Table 3. Responses of staff on promotion condition.

\begin{tabular}{ccccccc}
\hline Schools & A & B & C & D & E & Total \\
\hline 1 & 18 & 18 & 15 & 17 & 10 & 78 \\
2 & 20 & 17 & 17 & 15 & 11 & 80 \\
3 & 19 & 20 & 14 & 14 & 10 & 77 \\
4 & 17 & 18 & 17 & 16 & 8 & 76 \\
Total & 74 & 73 & 63 & 62 & 39 & 311
\end{tabular}

Source: survey result from Imo State University, 2020.

Table 4. Responses of staff on career choices.

\begin{tabular}{ccccc}
\hline Response & Agree & Disagree & Non & Total \\
\hline$\%$ & 43.73 & 40.84 & 15.43 & 100 \\
\hline
\end{tabular}

Table 5. Responses of staff on career choices.

\begin{tabular}{ccccc}
\hline Response & Agree & Disagree & Non & Total \\
\hline$\%$ & 47.59 & 37.30 & 15.11 & 100
\end{tabular}

Table 6. Responses of staff on career choices.

\begin{tabular}{ccccc}
\hline Response & Agree & Disagree & Non & Total \\
\hline$\%$ & 47.27 & 40.19 & 12.54 & 100 \\
\hline
\end{tabular}


From the descriptive statistical analysis, we cannot make any generalization because the analysis is restricted to the sample data under consideration. For us to make reasonable conclusion from this study, we make use of inferential statistics and test the proposed hypothesis and make a generalized conclusion that cut across the entire population.

\section{Inferential Analysis}

Using Equations (1) and (2), we compute as follows:

$$
\begin{gathered}
\chi_{c a l}^{2}=\sum_{i=1}^{n} \sum_{j=1}^{m} \frac{\left(O_{i j}-E_{i j}\right)^{2}}{E_{i j}} \\
\chi^{2}=\frac{(18-18.04)^{2}}{18.04}+\frac{(20-19.13)^{2}}{19.13}+\frac{(17-17.22)^{2}}{17.22}+\cdots+\frac{(10-11.27)^{2}}{11.27} \\
\chi_{c a l}^{2}=5.29 \\
\chi_{(c-1)(r-1)}^{2} \alpha=\chi_{12}^{2}(0.05)=5.23
\end{gathered}
$$

\section{Decision}

Reject Ho: if $\chi_{c a l}^{2}>\chi^{2} \alpha$ and accept if otherwise:

\section{Answer to Research Hypothesis (1)}

Since the value of $\chi_{\text {cal }}^{2}=5.29>\chi_{\alpha}^{2}=5.23$, we reject Ho: and accept H1: and conclude that career choices of Imo State University staff are dependent on their gender.

$$
\begin{gathered}
\chi_{c a l}^{2}=\sum_{i=1}^{n} \sum_{j=1}^{m} \frac{\left(O_{i j}-E_{i j}\right)^{2}}{E_{i j}} \\
\chi^{2}=\frac{(15-16.84)^{2}}{16.84}+\frac{(19-19.81)^{2}}{19.81}+\frac{(15-15.10)^{2}}{15.10}+\cdots+\frac{(12-12.09)^{2}}{12.09} \\
\chi_{c a l}^{2}=6.012
\end{gathered}
$$

Table 7. Analysis of data in Table 1.

\begin{tabular}{ccccccc}
\hline Schools & A & B & C & D & E & Total \\
\hline 1 & $18(18.04)$ & $20(19.13)$ & $17(17.22)$ & $20(17.49)$ & $10(13.12)$ & 85 \\
2 & $14(16.55)$ & $19(17.56)$ & $15(15.80)$ & $15(16.05)$ & $15(12.04)$ & 78 \\
3 & $20(15.92)$ & $14(17.56)$ & $15(15.19)$ & $13(15.43)$ & $13(11.58)$ & 75 \\
4 & $14(15.49)$ & $17(16.43)$ & $16(14.79)$ & $16(15.02)$ & $10(11.27)$ & 73 \\
Total & $\mathbf{6 6}$ & $\mathbf{7 0}$ & $\mathbf{6 3}$ & $\mathbf{6 4}$ & $\mathbf{4 8}$ & $\mathbf{3 1 1}$ \\
\hline
\end{tabular}

Table 8. Analysis of data in Table 2.

\begin{tabular}{ccccccc}
\hline Schools & $\mathbf{A}$ & $\mathbf{B}$ & $\mathbf{C}$ & $\mathbf{D}$ & $\mathbf{E}$ & Total \\
\hline 1 & $15(16.84)$ & $19(19.81)$ & $15(15.10)$ & $14(13.62)$ & $14(11.64)$ & 77 \\
2 & $16(14.87)$ & $13(17.49)$ & $18(13.34)$ & $11(12.03)$ & $10(10.28)$ & 68 \\
3 & $19(18.80)$ & $26(22.12)$ & $13(16.87)$ & $17(15.21)$ & $11(13.00)$ & 86 \\
4 & $18(17.49)$ & $22(20.58)$ & $15(15.69)$ & $13(14.15)$ & $12(12.09)$ & 80 \\
Total & $\mathbf{6 8}$ & $\mathbf{8 0}$ & $\mathbf{6 1}$ & $\mathbf{5 5}$ & $\mathbf{4 7}$ & $\mathbf{3 1 1}$ \\
\hline
\end{tabular}


Table 9. Analysis of data in Table 3.

\begin{tabular}{ccccccc}
\hline Schools & A & B & C & D & E & Total \\
\hline 1 & $18(18.56)$ & $18(18.31)$ & $15(15.80)$ & $17(15.55)$ & $10(9.78)$ & 78 \\
2 & $20(19.04)$ & $17(18.78)$ & $17(16.21)$ & $15(15.95)$ & $11(10.03)$ & 80 \\
3 & $19(18.32)$ & $20(18.07)$ & $14(15.60)$ & $14(15.35)$ & $10(9.66)$ & 77 \\
4 & $17(18.08)$ & $18(17.84)$ & $17(15.40)$ & $16(15.15)$ & $8(9.53)$ & 76 \\
Total & 74 & 73 & 63 & 62 & 39 & 311 \\
\hline & \multicolumn{7}{c}{$\chi_{(c-1)(r-1)}^{2} \alpha=\chi_{12}^{2}(0.05)=5.23$} \\
\end{tabular}

\section{Decision}

Reject Ho: if $\chi_{\text {cal }}^{2}>\chi^{2} \alpha$ and accept if otherwise:

\section{Answer to Research Hypothesis (2)}

Since the value of $\chi_{\text {cal }}^{2}=6.012>\chi_{\alpha}^{2}=5.23$, we reject Ho: and accept H1: and conclude that Employment of the staff of Imo State University is dependent of gender.

$$
\begin{gathered}
\chi_{c a l}^{2}=\sum_{i=1}^{n} \sum_{j=1}^{m} \frac{\left(O_{i j}-E_{i j}\right)^{2}}{E_{i j}} \\
\chi^{2}=\frac{(18-18.56)^{2}}{18.56}+\frac{(18-18.31)^{2}}{18.31}+\frac{(15-15.80)^{2}}{15.80}+\cdots+\frac{(8-9.53)^{2}}{9.53} \\
\chi_{\text {cal }}^{2}=0.525 \\
\chi_{(c-1)(r-1)}^{2} \alpha=\chi_{12}^{2}(0.05)=5.23
\end{gathered}
$$

\section{Decision}

Reject Ho: if $\chi_{\text {cal }}^{2}>\chi^{2} \alpha$ and accept if otherwise:

\section{Answer to Research Hypothesis (3)}

Since the value of $\chi_{\text {cal }}^{2}=0.525<\chi_{\alpha}^{2}=5.23$, we accept Ho: and reject H1: and conclude that staff promotion in Imo State University is independent of gender.

\subsection{Results}

From the descriptive analysis carried out in Table 4, it was observed that $43.73 \%$ were of the opinion that they were not influenced by gender while making their career choices, while $40.84 \%$ of the staff was of the opinion that their gender determines their choice of careers. From Table 5, we observed that $47.59 \%$ were of the opinion that their employment do not dependent of their gender, while $37.30 \%$ of the staff believed that their employment depend on their on their gender. Finally, from Table 6 , we observed that $47.27 \%$ were of the opinion that their promotion do not dependent on their gender, while $40.19 \%$ of the staff believed that their promotion was based on their gender. The descriptive statistical analysis indicates fair gender balance in the university with respect to staff's career choice, employment and promotion. 
From the inferential analysis obtained from the three hypotheses, there were strong indications that gender consideration is significant in career choices; employment but not promotion of staff in Imo State University, Owerri. And by extension, this research does not support the claim that there is gender discrimination. The researcher concludes that there is no supporting evidence of gender discrimination against women in Imo State University Owerri and by extension, there is no gender discrimination against women in Imo State Nigeria.

From the analysis we carried out in this study, we discovered that gender discrimination against women is not significant. We carried out three tests of hypotheses and conclude as follows: that career choices of Imo State University staff are dependent on their gender; Employment of the staff of Imo State University is dependent of gender, probably to maintain gender balance and finally, staff promotion in Imo State University is independent of gender. These results were based on the inferential analysis which cut across the entire university. On the other hand, descriptive statistics which was based on the sample selected for the study, we observed that gender doe not play a significant role in career choices, employment and promotion of the specified staff used for the study. But our major focus is on the inferential analysis which is general to the entire staff of the university and beyond.

\section{Summary and Conclusion}

This study indicates that there is a strong reason to believe that there is no gender discrimination against women. We suggest that equal opportunities should continuously be maintained between male and their female counterparts in work places. Women should be encouraged to enroll in those courses that are dominated by men so as to have gender balance in that area.

\section{Conflicts of Interest}

The author declares no conflicts of interest regarding the publication of this paper.

\section{References}

Arua, A. I., Chukwu, W. I. E., Okafor, F. C., \& Ugwuowo, F. I. (1997). Fundamentals of Statistics for Higher Education (p. 133). Fijac Academic Press.

Buser, T., Niederle, M., \& Oosterbeek, H. (2014). Gender, Competitiveness, and Career Choices. The Quarterly Journal of Economics, 129, 1409-1447. https://doi.org/10.1093/qje/qju009

Callahan, M. N. (2015). The Right Attitude: Gender, Conservatism, and Career Choice. Master's Dissertations, No. 14333, Iowa State University. https://lib.dr.iastate.edu/etd/14333

Conner, A. L., Cook, K. S., Correll, S. J., Markus, H. R., Moss-Racusin, C. A., Muller, C. B., Raymond, J. L., \& Simard, C. (2014). Obscuring Gender Bias with “Choice”. Science, 343, 1200. https://doi.org/10.1126/science.343.6176.1200-a

Correll, S. J. (2001). Gender and the Career Choice Process: The Role of Biased Self-Assess- 
ments. American Journal of Sociology, 106, 1691-1730.

https://doi.org/10.1086/321299

Fluhr, S. A., Choi, N., Herd, A., Woo, H., \& Alagaraja, M. (2017). Gender, Career and Technical Education (CTE) Nontraditional Coursetaking, and Wage Gap. The High School Journal, 100, 166-182. https://doi.org/10.1353/hsj.2017.0006

Gibson, D. E., \& Lawrence, B. S. (2010). Women's and Men's Career Referents: How Gender Composition and Comparison Level Shape Career Expectations. Organization Science, 21, 1159-1175. https://doi.org/10.1287/orsc.1090.0508

Herrbach, O., \& Mignonac, K. (2012). Perceived Gender Discrimination and Women's Subjective Career Success: The Moderating Role of Career Anchors. Relations Indstrielles/Industrial Relations, 67, 25-50. https://doi.org/10.7202/1008194ar

Mullen, A. L. (2014). Gender, Social Background, and the Choice of College Major in a Liberal Arts Context. Gender and Society, 28, 289-312. https://doi.org/10.1177/0891243213512721

Raggl, A., \& Troman, G. (2008). Turning to Teaching: Gender and Career Choice. British Journal of Sociology of Education, 29, 581-595.

https://doi.org/10.1080/01425690802423254

Tang, M., Pan, W., \& Newmeyer, M. D. (2008). Factors Influencing High School Students' Career Aspirations. Professional School Counseling, 11, 285-295.

Taro, Y. (1967). Statistics: An Introductory Analysis (2nd ed., p. 283). Harper and Row Publisher.

Zafar, B. (2013). College Major Choice and the Gender Gap. The Journal of Human Resources, 48, 545-595. https://doi.org/10.3368/jhr.48.3.545 